\title{
Cultura e discurso: uma análise translinguística de interações de teletandem
}

\author{
Culture and discourse: a translinguistic analysis of teletandem interactions
}

Maisa de Alcântara Zakir

UNESP - São José do Rio Preto - São Paulo - Brasil

\begin{abstract}
Resumo: O projeto Teletandem e Transculturalidade na interação on-line em línguas estrangeiras por webcam é desenvolvido desde 2010 e coloca aprendizes de línguas estrangeiras no Brasil em contato com aprendizes de língua portuguesa no exterior em interações via Skype. $\mathrm{O}$ contexto no qual este estudo se desenvolveu é denominado teletandem institucional semiintegrado, por ser integrado ao currículo da universidade estrangeira parceira do projeto e nãointegrado ao currículo da universidade brasileira. O objetivo do trabalho é analisar interações de teletandem entre uma aluna do curso intermediário de língua portuguesa de uma universidade privada estadunidense e um professor aprendiz de inglês como língua estrangeira que trabalha em uma universidade pública brasileira. As interações entre os participantes da pesquisa foram analisadas na perspectiva da Análise Dialógica do Discurso, fundamentada na obra de Bakhtin e do Círculo. Os resultados da análise evidenciam os papéis sociais identificados no discurso dos interagentes em discussões sobre aspectos culturais.
\end{abstract}

Palavras-chave: Teletandem institucional; Análise dialógica do discurso; Papéis sociais

\begin{abstract}
The Project entitled Teletandem and Transculturality in online interaction in foreign languages by webcam has been developed since 2010 and has put learners of foreign languages in Brazil in touch with learners of Portuguese abroad in interactions via Skype. The context in which this study was developed is called semi-integrated institutional teletandem, being integrated into the curriculum of the foreign university partner in the project and non-integrated into the curriculum of the Brazilian university. This paper aims at analyzing teletandem interactions between a female student of intermediate Portuguese in a private American university and a professor who studies English as a foreign language who works at a Brazilian public university. The interactions between the participants were analyzed under the perspective of Dialogic Discourse Analysis, grounded on the work of Bakhtin and the Circle. The analysis results show the social roles identified in the participants' discourse when discussing cultural aspects.
\end{abstract}

Keywords: Institutional teletandem; Dialogic discourse analysis; Social Roles

\section{Introdução}

$\mathrm{O}$ ensino de LE tem se transformado à medida que o avanço tecnológico ocupa um lugar cada vez mais expressivo nas práticas docentes. $\mathrm{O}$ acesso a outras línguas e culturas por meio de recursos que, em tempo real, colocam pessoas de diferentes partes do mundo em contato umas com as outras diminui fronteiras geográficas que, até pouco tempo atrás, dificultavam essa comunicação.

No escopo da Comunicação mediada por computador (CMC) e da aprendizagem de língua assistida por computador (CALL - Computer-Assisted Language Learning), à medida que cresce a quantidade de instituições que incluem a tecnologia como componente essencial na didática de LE, é fundamental pensar o conceito de telecolaboração. De acordo com Belz (2003), em sua clássica definição,

A telecolaboração envolve a aplicação de redes globais de computador para a aprendizagem de língua estrangeira (e segunda língua) em ambientes institucionalizados. Em parcerias telecolaborativas, aprendizes internacionalmente dispersos paralelamente nas aulas de língua utilizam ferramentas de 
comunicação pela internet, tais como e-mail, bate-papo síncrono, fóruns de discussão, e MOOs [MUD - Multiuser domain - Object Oriented] (bem como outras formas de comunicação eletronicamente mediada) para dar suporte à interação social, ao diálogo, ao debate e à troca intercultural. ${ }^{1}$ (p. 2)

Para O'Dowd (2011), a telecolaboração refere-se à utilização de "ferramentas de comunicação online para reunir grupos de aprendizes de línguas em locais geograficamente distantes para desenvolver suas habilidades linguísticas e competência intercultural por meio de tarefas colaborativas e trabalho de projeto" 2 (p. 342). Mais recentemente, o termo telecolaboração tem sido substituído por Online Interaction and Exchange (OIE). (DOOLY \& O'DOWD, 2012).

Uma das formas de se trabalhar com a telecolaboração no ensino de línguas que mais tem se destacado nas práticas atuais é a aprendizagem em teletandem, termo criado por Telles (2006). A proposta de aprendizagem de línguas em teletandem fundamenta-se nos princípios da aprendizagem em tandem, descritos por Brammerts (1996): autonomia, reciprocidade e separação de línguas. Devido à facilidade de locomoção entre pessoas de países da Europa e ao frequente contato cultural entre elas, a prática de tandem presencial é antiga naquele continente. Entretanto, no Brasil, embora o fluxo de estrangeiros seja grande em certas regiões, sobretudo em grandes centros comerciais, a prática de tandem presencial, comum na Europa, ainda é inviável e bem pouco difundida em muitos lugares do país.

Considerando essa situação, pode-se dizer que o projeto teletandem tem uma dimensão política, na medida em que possibilita a alunos universitários brasileiros tanto o acesso democrático às línguas estrangeiras como o contato com alunos estrangeiros, sobretudo àqueles que não têm a oportunidade de realizar um intercâmbio no exterior. Isso porque o teletandem é um contexto virtual síncrono e colaborativo de aprendizagem que envolve dois falantes nativos (ou proficientes) de diferentes línguas (TELLES, 2006; TELLES \& VASSALLO, 2009). Os parceiros trabalham de forma colaborativa, utilizando recursos de voz, texto e imagens de webcam do Skype, a fim de aprenderem a língua um do outro.

\footnotetext{
No original: "Telecollaboration involves the application of global computer networks to foreign (and second) language learning and teaching in institutionalized settings. In telecollaborative partnerships, internationally-dispersed learners in parallel language classes use Internet communication tools such as e-mail, synchronous chat, threaded discussion, and MOOs (as well as other forms of electronically mediated communication), in order to support social interaction, dialogue, debate, and intercultural exchange." (BELZ, 2003, p. 2).

2 No original: "[...] online communication tools to bring together classes of language learners in geographically distant locations to develop their foreign language skills and intercultural competence through collaborative tasks and project work."
}

O tempo é dividido em duas partes iguais, nas quais os parceiros interagem em uma língua de cada vez, ajudando o outro a aprender a sua língua. Ao final da primeira parte, os parceiros trocam, então, de papéis e de línguas.

Fundamentando-se em Brammerts et al. (2002), que classifica a prática de tandem em modalidades determinadas pelas características do contexto, Aranha \& Cavalari (2014) denominam as interações da primeira fase do projeto Teletandem Brasil como "teletandem institucional não-integrado", uma vez que os envolvidos eram vinculados a uma instituição de ensino, mas não havia a obrigatoriedade de a prática estar inserida formalmente no currículo de um curso.

$\mathrm{Na}$ do projeto Teletandem e transculturalidade, desenvolvido a partir de 2010, a consolidação de parcerias com universidades estrangeiras levou os pesquisadores brasileiros a realizarem sessões de teletandem envolvendo turmas inteiras de alunos estrangeiros de português como língua estrangeira e grupos de alunos brasileiros nos laboratórios das universidades participantes. Atualmente os alunos são colocados em pares que, na maioria das vezes, se mantêm ao longo do semestre e realizam a interação, que é acompanhada pelo professor da turma, no caso das universidades estrangeiras, e pelo professor dos alunos, ou por um pesquisador do projeto, no caso da universidade brasileira (doravante UB).

A modalidade na qual a prática de teletandem faz parte do programa do curso de língua estrangeira é chamada por Aranha \& Cavalari (2014) de teletandem institucional integrado (doravante TTii). Os alunos brasileiros, embora não necessariamente pratiquem teletandem como requisito de seu curso de graduação, como é o caso dos alunos estrangeiros, são acompanhados por mediadores, os quais podem ser professores e/ou pesquisadores em teletandem da instituição brasileira. Nesse caso, quando apenas uma das instituições de ensino adota a prática como parte do currículo, temos duas modalidades de teletandem: institucional integrado e não-integrado. Messias (mimeo) classifica essa modalidade como Teletandem institucional semi-integrado, quando apenas uma das universidades parceiras adota a prática de teletandem como parte do currículo.

A institucionalização do teletandem possibilitou o desenvolvimento de parcerias de ensino e pesquisa entre universidades brasileiras e estrangeiras. Os dados analisados neste trabalho resultam de uma dessas parcerias, na qual atuei como professora de língua portuguesa em uma universidade estadunidense (doravante UE) no ano de 2012 para coletar o material pesquisado. A fundamentação teórico-metodológica é detalhada no item a seguir. 


\section{Fundamentação teórico-metodológica}

A questão da linguagem como lugar de manifestação concreta da ideologia (BAKHTIN/VOLOCHINOV, 2004) é o elemento fundador da perspectiva teóricometodológica que orienta este trabalho. O pensamento bakhtiniano é resultado não apenas da obra escrita por Bakhtin, mas do que hoje é conhecido como "Círculo de Bakhtin", formado por intelectuais russos de diferentes áreas do conhecimento que tinham a linguagem como ponto de referência (BRAIT, 2010; 2013).

A obra de Bakhtin ganhou notoriedade com suas importantes contribuições para a literatura, a filosofia da linguagem e os estudos linguísticos há relativamente pouco tempo, se comparada à de outros pensadores, como Saussure, que já imprimiram tradição nas teorias das referidas áreas do conhecimento. Foi na década de 1980 que diferentes países passaram a ter acesso ao pensamento bakhtiniano, primeiramente em seus trabalhos sobre literatura e depois no campo linguístico (PAULA, 2013).

Segundo Kramsch (2009), o interesse por Bakhtin entre os estudiosos da linguagem coincide com a percepção de que o ensino de línguas não precisa estar vinculado a teorias estruturalistas, que veem a língua como separadas de sua realidade. Este trabalho apoia-se, em termos metodológicos, na vertente que foi chamada no Brasil de Análise Dialógica do Discurso (ADD).

De acordo com Brait (2010), essa perspectiva teóricometolodológica fundamenta-se, sobretudo, na proposta de Bakhtin, em Problemas da poética de Dostoiévski, de criar uma disciplina chamada "Metalinguística" ou "Translinguística."3 Bakhtin (2013a), ao analisar as relações dialógicas na construção da linguagem nas obras de Dostoiévski, constata que tais relações são impossíveis sob uma perspectiva rigorosamente linguística. No entanto, Fiorin (2011) esclarece que, ao contrário do que certas leituras equivocadas da obra de Bakhtin fazem crer, o filósofo russo não nega a existência do sistema da língua e não condena seu estudo; apenas propõe a disciplina translinguística porque entende que a linguística não explica o modo de funcionamento real da linguagem. A proposta de Bakhtin, portanto, considera que

A linguística conhece, evidentemente, a forma composicional do 'discurso dialógico' e estuda as suas particularidades sintáticas léxico-semânticas. Mas ela as estuda como fenômenos puramente linguísticos,

\footnotetext{
3 Embora a tradução brasileira do livro A poética de Dostoiévski utilize o termo metalinguística, adotado por Brait (2010), neste trabalho adoto o termo translinguística, em consonância com estudiosos brasileiros como Fiorin (2011) e Paula (2013). Fiorin (2011) justifica sua escolha pelos valores semânticos que envolvem metalinguística e explica que os prefixos meta (grego) e trans (latino) são equivalentes do ponto de vista do sistema.
}

ou seja, no plano da língua, e não pode abordar, em hipótese alguma, a especificidade das relações dialógicas entre as réplicas. Por isso, ao estudar o 'discurso dialógico', a linguística deve aproveitar os resultados da metalinguística. (BAKHTIN, 2013a, p. 209).

Assim, a translinguística tem por objeto "o exame das relações dialógicas entre os enunciados, seu modo de constituição real" (FIORIN, 2011, p. 33), levando em conta a historicidade do discurso. É desta perspectiva que analiso os dados das interações entre os participantes da presente pesquisa. Do ponto de vista bakhtiniano, é por meio da linguagem que se constituem a sociedade e a cultura. Nesse sentido, o teletandem é o contexto no qual esses três conceitos estão entremeados e as interações em língua materna e estrangeira são analisadas, neste trabalho, discursivamente em suas dimensões linguística e translinguística.

Uma das contribuições do teletandem para a área de ensino e aprendizagem de LE consiste, justamente, em trazer em seu bojo a língua em movimento e, portanto, como organismo vivo, tal como a concebe Bakhtin/ Volochinov (2004), no "jogo" entre os interagentes. Desse ponto de vista, a perspectiva bakhtiniana possibilita pensarmos exatamente na questão social, na dimensão interativa da noção de cultura, porque a cultura está no social. Não se trata, portanto, de se pensar a cultura além da língua, mas de se levar em conta que a cultura e a sociedade estão $n a$ língua.

A concepção de língua na qual este trabalho se embasa difere, portanto, da proposta pelo objetivismo abstrato, cuja expressão principal é a teoria saussureana. Para Bakhtin/Volochinov (2004, p. 96), "a separação da língua de seu conteúdo ideológico constitui um dos erros mais grosseiros do objetivismo abstrato." Além disso, outro problema dessa orientação é que não se atribui sentido às palavras quando elas são entendidas apenas como itens de dicionário, como formas fixas. Ao contrário, no teletandem, assim como na concepção bakhtiniana, "[...] na prática viva da língua, a consciência lingüística do locutor e do receptor nada tem a ver com um sistema abstrato de formas normativas, mas apenas com a linguagem no sentido de conjunto dos contextos possíveis de uso de cada forma particular." (BAKHTIN/ VOLOCHINOV, 2004, p. 95).

Estabelecer a diferença entre tais concepções não quer dizer, no entanto, que não seja necessário entender os níveis estruturais da língua para poder analisar aquilo que é translinguístico, ou seja, aquilo que ultrapassa os limites da linguística e está no nível discursivo. Assim, na análise dos dados a seguir são consideradas essas duas dimensões. 
Ao explicar a disciplina que propõe, Bakhtin (2013a) confere a seu objeto de estudo uma dimensão extralinguística:

[...] as relações dialógicas são extralingüísticas. Ao mesmo tempo, porém, não podem ser separadas do campo do discurso, ou seja, da língua enquanto fenômeno integral concreto. A linguagem só vive na comunicação dialógica daqueles que a usam. É precisamente essa comunicação dialógica que constitui o verdadeiro campo da vida da linguagem. Toda a vida da linguagem, seja qual for o seu campo de emprego (a linguagem cotidiana, a prática, a científica, a artística, etc.), está impregnada de relações dialógicas. Mas a Lingüística estuda a linguagem propriamente dita com sua lógica específica na sua generalidade, como algo que torna possível a comunicação dialógica, pois ela abstrai conseqüentemente as relações propriamente dialógicas. Essas relações se situam no campo do discurso, pois este é por natureza dialógico e, por isto, tais relações devem ser estudadas pela Metalingüística, que ultrapassa os limites da Lingüística e possui objeto autônomo e metas próprias. (BAKHTIN, 2013a, p. 209).

Fiorin (2011, p. 34), ao discorrer sobre as categorias de análise em Bakhtin, esclarece que "qualquer análise linguística pode ser utilizada como base de uma análise translinguística [...] Assim, numa análise translinguística, é preciso analisar as significações do texto, para, a partir daí, examinar as relações com o que está fora dele."

O embasamento constitutivo da teoria dialógica do discurso, segundo Brait (2010), postula

a indissolúvel relação existente entre língua, linguagens, história e sujeitos que instaura os estudos da linguagem como lugares de produção de conhecimento de forma comprometida, responsável, e não apenas como procedimento submetido a teorias e metodologias dominantes em determinadas épocas. Mais ainda, esse embasamento constitutivo diz respeito a uma concepção de linguagem, de construção e produção de sentidos necessariamente apoiadas nas relações discursivas empreendidas por sujeitos historicamente situados. (BRAIT, 2010, p. 10)

Nesse sentido, a historicidade e o dialogismo são constitutivos do discurso, como vimos anteriormente na definição de Bakhtin (2013a). A respeito do dialogismo constitutivo do discurso, Fiorin (2011) pontua que

a palavra do outro é condição necessária para a existência de qualquer discurso, sob um discurso há outro discurso. Essas duas vozes não precisam estar marcadas no fio do discurso, elas são apreendidas pelo nosso conhecimento dos diferentes discursos que circulam numa dada época numa determinada formação social. (FIORIN, 2011, p. 40).
De acordo com Brait (2013, p. 88), "É a bivocalidade de 'dialógico', situado no objeto e na maneira de enfrentálo, que caracteriza a novidade da Metalinguística/ Translinguística e de suas consequências para os estudos da linguagem."

Muito embora não haja, sistematicamente, uma proposta formal de análise de discurso deixada por Bakhtin e o Círculo (BRAIT, 2010; SOBRAL, 2013; PAULA, 2013), é inegável que "o conjunto das obras do Círculo motivou o nascimento de uma análise/teoria dialógica do discurso, perspectiva cujas influências e consequências são visíveis nos estudos linguísticos e literários e também nas Ciências Humanas de maneira geral (BRAIT, 2010, p. 9-10). Escolher tal perspectiva teórico-metodológica implica enfrentar o desafio de se trabalhar com uma proposta que não tem, por exemplo, a consolidação e a sistematização da linha francesa, proposta formalmente como teoria dos estudos do discurso. No entanto, implica também a responsabilidade de se "ressaltar a origem filosófica, ética e estética que constitui a gênese do pensamento bakhtiniano como um todo. (BRAIT, 2010, p. 15).

Tendo em vista que a base marxista da filosofia da linguagem bakhtiniana é também a base da teoria do desenvolvimento humano e da aprendizagem formulada por Vigostki, a Análise Dialógica do Discurso configura-se como uma escolha ao mesmo tempo desafiadora, por sua chegada relativamente recente no campo metodológico, e coerente, por seu fundamento filosófico que dialoga com a concepção de linguagem que tem embasado as pesquisas dos projetos Teletandem Brasil e Teletandem e transculturalidade.

Além disso, é importante ressaltar um ponto importante na escolha teórico-metodológica deste trabalho: o princípio do dialogismo na teoria bakhtiniana se dá a partir da constituição do eu pelo outro (BAKHTIN, 1981; FIORIN, 2010, 2011). No teletandem, a julgar pelas pesquisas realizadas no projeto TTB até o momento e pelo próprio caráter interativo das sessões, esse princípio parece ser, ao mesmo tempo, corroborado e corroborador. Isso porque, tendo em vista que dois interlocutores são colocados em contato, a sessão de teletandem constituise como um espaço de trocas nas quais são evidenciados diferentes discursos que dialogam entre si.

Como esclarece Fiorin (2010, p. 166), "O dialogismo é sempre entre discursos. O interlocutor só existe enquanto discurso. Há, pois, um embate de dois discursos: o do locutor e o do interlocutor, o que significa que o dialogismo se dá sempre entre discursos".

Se pensarmos nos participantes da pesquisa como sujeitos situados cultural e socialmente no contexto teletandem, seja ele institucional integrado (nos EUA) ou não-integrado (no Brasil), as possibilidades de 
diálogo extrapolam ainda mais o "lugar" que ocupam. $\mathrm{O}$ contato intercultural entre os interagentes parece lançar evidências de que é criada uma relação que está além das fronteiras geográficas, situando-se, portanto, na esfera da terceiridade, entendida como terceiro espaço da enunciação (BHABHA, 1998), ou, como postula o princípio do dialogismo bakhtiniano, na constituição do eu pelo outro.

Brait (2013) destaca alguns aspectos que caracterizam a Análise Dialógica do Discurso que podem ser considerados elementos-chave no tratamento dos dados coletados para a realização de uma pesquisa:

a) o reconhecimento da multiplicidade de discursos que constituem um texto ou um conjunto de textos que modificam, alteram ou subvertem suas relações, por força da mudança de esfera de circulação e recepção; b) o discurso, definido como relações dialógicas, tomado como objeto de uma disciplina interdisciplinar, denominada por Bakhtin metalinguística ou translinguística, e que hoje pode ser tomada como embrião da análise/teoria dialógica do discurso; c) o pressuposto teórico-metodológico de que as relações dialógicas se estabelecem a partir de ponto de vista assumido por um sujeito histórico, social, cultural; d) as consequências teórico-metodológicas de que as relações dialógicas não são dadas, não estando, portanto, jamais prontas e acabadas num determinado objeto de pesquisa, mas sempre estabelecidas a partir de um ponto de vista moldado por valores, tensões, fronteiras; e) o papel das linguagens e dos sujeitos na construção dos sentidos; f) a concepção de texto como assinatura de um sujeito, individual ou coletivo, que mobiliza discursos históricos, sociais e culturais para constituí-lo e constituir-se. (BRAIT, 2013, p. 85)

Tomando esses aspectos como princípios teóricos orientadores, a interpretação dos dados desta pesquisa considera a produção de sentidos como parte integrante das atividades sociais dos participantes do estudo. Essa proposta vai ao encontro do pensamento de Fernandes (2008, p. 15), para quem "a ideologia materializa-se no discurso que, por sua vez, é materializado pela linguagem em forma de texto; e/ou pela linguagem não-verbal em forma de imagens."

É por meio do exercício de exotopia que faço esse exercício de interpretação. Ao analisar os dados coletados em um contexto em que atuei como professora de uma das turmas participantes desta pesquisa, não apenas existe uma outra dimensão espaço-temporal, mas também uma outra constituição de vozes sociais: da então professora para a de pesquisadora, cujo discurso está presente ao longo de todo este trabalho. É justamente nesse exercício de exotopia que Amorim (2004) propõe que se pense a questão da alteridade, no caso deste trabalho, a relação entre o eu-professora/mediadora dos participantes da pesquisa e o eu-pesquisadora, que analisa os dados produzidos naquele contexto. Amorim (2004) postula, portanto, que é na alteridade que está uma grande parte do trabalho do pesquisador:

Análise e manejo das relações com o outro constituem, no trabalho de campo e no trabalho de escrita, um dos eixos em torno dos quais se produz o saber. Diferença no interior de uma identidade, pluralidade na unidade, o outro é ao mesmo tempo aquele que quero encontrar e aquele cuja impossibilidade de encontro integra o próprio princípio da pesquisa. Sem reconhecimento da alteridade não há objeto de pesquisa e isto faz com que toda tentativa de compreensão e de diálogo se construa sempre na referência aos limites dessa tentativa. (AMORIM, 2004, p. 28-29).

É nessa tentativa de compreender o lugar da cultura no teletandem que minha voz de pesquisadora considera todo o "conjuntamente visto" (expressão usada por Volochinov/Bakhtin em Discurso na Vida e Discurso na Arte, ao exemplificar o contexto extraverbal do enunciado) para analisar os dados coletados para este trabalho. Na medida em que os elementos contextuais extraverbais do cenário da pesquisa são cruciais para a interpretação do material produzido pelos participantes, há um olhar global, que enxerga as situações em questão, considerando-se, sempre, pontos específicos de cada uma delas.

As Ciências Humanas são entendidas como ciências do texto/discurso pelos pesquisadores que estudam Bakhtin (AMORIM, 2010; PAULA, 2013), na medida em que o fato de produzir textos é o que constitui nos sujeitos seu caráter fundamentalmente humano. No caso dos dados que compõem o corpus desta pesquisa, tal perspectiva é pensada nas várias esferas nas quais esses textos são produzidos pelos envolvidos no contexto da pesquisa: interações orais com webcam durante as sessões de teletandem, atividades escritas na plataforma virtual, bem como o texto deste trabalho propriamente dito, escrito pela pesquisadora sobre o material coletado. Amorim (2010) assim explica a relação entre pesquisador e sujeito pesquisado:

Pesquisador e sujeito pesquisado são ambos produtores de texto, o que confere às Ciências Humanas um caráter dialógico. Uma primeira consequência disto é que o texto do pesquisador não deve emudecer o texto do pesquisado, deve restituir as condições de enunciação e de circulação que lhe conferem as múltiplas possibilidades de sentido. Mas o texto do pesquisado não pode fazer desaparecer o texto do pesquisador, como se este se eximisse de qualquer afirmação que se distinga do que diz o pesquisado. $\mathrm{O}$ fundamental é que a pesquisa não realize nenhum tipo de fusão dos dois pontos de vista, mas que mantenha 
o caráter de diálogo, revelando sempre as diferenças e a tensão entre elas. Importante ressaltar que esse diálogo não é simétrico e aqui reaparece o conceito de exotopia. O pesquisador deve fazer intervir sua posição exterior: sua problemática, suas teorias, seus valores, seu contexto sócio-histórico, para revelar do sujeito algo que ele mesmo não pode ver. (AMORIM, 2010, p. 98)

Destarte, num exercício de exotopia e de diálogo com o contexto de pesquisa, todo o material produzido (textos orais e escritos, imagens de webcam, síncronos ou assíncronos, presencial ou virtualmente) pelos participantes durante o período em que praticaram teletandem são considerados para dar mais elementos à interpretação dos dados e explorar o máximo possível as questões de natureza linguística e, portanto, sociais e ideológicas, impregnadas na multiplicidade de discursos materializados.

É também por meio do exercício de exotopia que entendo o modo como as interações entre os participantes da pesquisa se dão, quando discutem questões relacionadas a suas culturas. A proposta deste trabalho de discutir os dados de pesquisa à luz da perspectiva dialógica do discurso implica considerar as "especificidades discursivas constitutivas de situações em que a linguagem e determinadas atividades se interpenetram e interdefinem, e do compromisso ético do pesquisador com o objeto, que, dessa perspectiva, é um sujeito histórico." (BRAIT, 2010, p. 29).

Desse modo, ao trazer à tona um tema complexo e multifacetado, discuto pontos de vista nem sempre consensuais entre indivíduos de diferentes culturas. A própria escolha teórico-metodológica, fundamentada nos pressupostos do dialogismo bakhtiniano, já é um indício de que este trabalho se desenvolve no embate, nos choques discursivos, nos contrapontos, na constituição do sujeito pela relação entre o eu e o outro e, portanto, de modo dialógico. Na seção a seguir apresento os participantes da pesquisa e, à luz da perspectiva translinguística, analiso parte das interações que realizaram durante o primeiro semestre de 2012.

\section{Análise e discussão dos dados}

Ashley e Orlando ${ }^{4}$ realizaram dez interações de teletandem no primeiro semestre de 2012, das quais as cinco últimas foram gravadas e transcritas. Na ocasião, Ashley tinha 21 anos. Ela nasceu na cidade onde está localizada a UE. Sua família é de origem cubana e ela fala fluentemente inglês e espanhol. Estuda Biologia e revela planos de

\footnotetext{
4 Os nomes dos participantes da pesquisa são fictícios. Os dados foram coletados mediante autorização do comitê de ética das duas universidades participantes e os termos de consentimento assinados pelos participantes encontram-se arquivados com a pesquisadora.

5 Sobre discurso de gênero em teletandem, ver Costa (2015).
}

seguir os estudos na faculdade de Medicina. Ashley mora com a família na cidade da UE e, além de estudar na universidade, trabalha como vendedora em uma loja.

Orlando é professor de Educação Física e trabalha na UB. Tinha cinquenta e três anos quando os dados da pesquisa foram coletados. Por meio das interações gravadas, sabemos que ele já viajou aos EUA e que, frequentemente, faz menções a suas experiências e conhecimentos sobre o país.

A dinâmica das interações entre os dois com o "domínio" de Orlando (LEONE, 2012) em relação aos assuntos tratados e aos turnos mais longos, pode ser explicada pelo papel social que assume independentemente da língua usada na interação (VASSALLO, 2010): homem $^{5}$, professor e mais experiente do que Ashley, não apenas em termos de idade, mas também por já ter visitado os EUA mais de uma vez e até morado no país.

Nas dinâmica das interações entre Ashley e Orlando, destacam-se principalmente as seguintes características: (1) ênfase de Orlando na aprendizagem do inglês, solicitando feedback da parceira; (2) papéis sociais e relações de hierarquia; (3) referências a preços de produtos e serviços, bens de consumo e $(\mathrm{m})$ comparações feitas entre EUA e Brasil; (4) generalizações e imagens estereotipadas. Neste trabalho, analiso o segundo eixo temático depreendido das interações entre Ashley e Orlando, papéis sociais e relações de hierarquia.

$\mathrm{O}$ excerto a seguir indica o posicionamento de Orlando, ao questionar a falta de tempo de Ashley. Há a evidência de certo desconforto dele pelo fato de a parceira não ter aberto um e-mail que ele lhe havia mandado. As linhas estão numeradas de acordo com os arquivos originais nos quais as transcrições foram salvas:

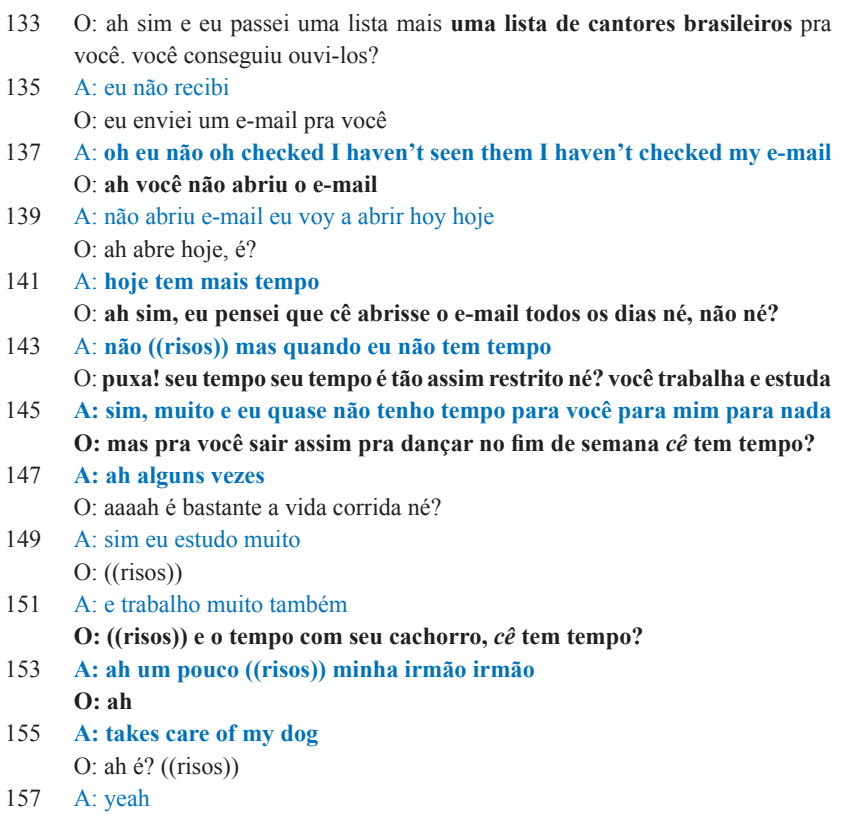
(Excerto 11-TT, Ashley e Orlando, 09/04/2012) 
Ao perguntar à parceira se ela tem tempo para sair para dançar (linha 146), Orlando parece ou duvidar de que ela não tenha, de fato, visto o e-mail, ou se incomodar porque ela não havia dado prioridade a algo que haviam combinado na sessão anterior. A conjunção adversativa "mas" (linha 146) tem um papel importante na construção da ironia utilizada por Orlando, que a questiona, de certo modo, sobre suas prioridades. O questionamento é reiterado adiante com a pergunta sobre o tempo de Ashley com seu animal de estimação (linha 152).

Em Questões de estilística no ensino da língua, Bakhtin trata dos efeitos de estilo no ensino da língua russa. Tais efeitos são analisados sob a perspectiva discursiva por um Bakhtin professor, que, ainda que trate da língua russa, deixa aos professores de língua materna e estrangeira contribuições no sentido de se ultrapassarem os limites de uma análise puramente estrutural da língua. Desse modo, entendemos, com Bakhtin (2013b), que a conjunção "mas" (linha 146), no excerto 11-TT, carrega em si os sentidos anteriores construídos na interação entre Ashley e Orlando. Esses sentidos são exteriores ao contexto daquela sessão, porque não apenas se referem a algo que Orlando esperava que Ashley fizesse entre a sessão anterior e aquela (ler o e-mail e ouvir os cantores brasileiros sugeridos por ele), mas também à própria constituição de seus papéis sociais.

Assim, Orlando assume uma posição hierarquicamente superior à da parceira, ao sutilmente lhe "dar uma bronca", como um pai ou um professor poderia fazê-lo. O discurso dele é, portanto, atravessado por esses papéis sociais que o constituem como sujeito: homem de meia idade, professor, aprendiz de inglês LE com boa proficiência, conhecedor do país da parceira etc. e falante nativo de português que sugere bons cantores para ela ouvir.

Ainda no que se refere à dinâmica das interações entre Ashley e Orlando, este assume o papel social de professor, trazendo informações que, ainda que ela já saiba, ele parece querer ensinar. No excerto 12-TT, a seguir, Orlando menciona o ex-presidente dos EUA, John Kennedy, lembrando que ele era católico, assim como o ator e ex-governador da Califórnia, Arnold Schwarzenegger, sobre quem eles estavam falando anteriormente. Orlando, provavelmente, tenha ressaltado este fato porque ele contrasta com a cultura religiosa predominantemente protestante dos EUA:

\footnotetext{
595 A: Probably yeah, I don't know a lot about him ((referindo-se a Arnold Schwarzenegger))

597 O: Yeah, and he is catholic too

A: he is catholic?

599 O: catholic, like John Kennedy, like the Kennedy's family A: oh, ok

601 O: the first, the number one, the unique, oh, president of the United States catholic

603 A: Kennedy?

O: Yeah, have you heard before?
}

605 A: Yeah, yeah, he is very popular, very popular here $\mathrm{O}$ : yeah, but he was a catholic, number one

607 A: yeah, the first, the first

O: the first catholic

609 A: fist catholic president

O: yeah, and

611 A: yeah, he was very popular here in the United States

O: oh, the Kennedy or Schwarzenegger? ((ironizando))

613 A: No, Kennedy ((riso)), oh Schwarzenegger a little bit, he's popular too $\mathrm{O}:(($ risos $))$

615 A: for being strong

$\mathrm{O}$ : very strong

617 A: very strong, look, I'm almost like strong like him, look at this ((mostra o bíceps e ri))

619 O: ((risos)) did you, do you pumping iron sometimes or no? A: ((risos)) pumping iron ((risos)), uh sometimes, I do a little bit of weight for my arms, but little weights

(Excerto 12-TT, Ashley e Orlando, 18/04/2012)

A pergunta "Have you heard before" (linha 604) é ambígua e não é possível saber com certeza se Orlando perguntava a Ashley se ela já tinha ouvido falar de John Kennedy ou do fato de que o famoso político havia sido o único presidente católico dos EUA. Em todo caso, ao perguntar à parceira mais adiante (linha 612) se ela se refere a Kennedy ou a Schwarzenegger quando afirma que "ele é popular", Ashley prontamente responde que é o primeiro, minimizando a importância política do segundo ("a little bit" - linha 613), dizendo que o astro hollywoodiano que se tornou governador da Califórnia é popular por ser forte (linha 615).

O excerto 12-TT evidencia um traço característico das interações entre Ashley e Orlando, uma vez que é frequente essa relação hierárquica, na qual se sobressai sua voz social de professor, ainda que a interação seja em inglês e Orlando, portanto, desempenharia o papel de aprendiz.

Do ponto de vista discursivo, o posicionamento de Orlando como o interagente que domina a interação (VASSALLO, 2010; LEONE, 2012) ecoa nos papéis sociais de ambos. Há, na relação, um jogo de poder envolvido: Orlando traz para as interações seu conhecimento de mundo, inclusive com muitas informações sobre os EUA e a(s) cultura(s) estadunidense(s), seu vasto repertório, já que transita facilmente pelos mais diversos assuntos; Ashley, em contrapartida, tem mais curiosidades com relação ao Brasil do que informações com as quais poderia confrontar Orlando.

No excerto a seguir, Ashley conta a Orlando que já fez uma viagem de carro, dirigindo da cidade onde mora até o estado de Nova Jersey:

\footnotetext{
538 A: I went to ((cidade onde está localizada a UE)), FROM ((cidade onde está localizada a UE)) to New Jersey and it took me like 25 hours, 26 hours

540 O: oh, have you ride before?

A: yeah, I've droven. But not to New York, to New Jersey

542 O: oh, to New Jer, oh, it's close

A: Yeah, it's close, it's like (incompreensível)

544 O: ah, and you consider a good driver? are you a, are you a

A: No! ((risos))

546 O: you are not a good driver?
} 


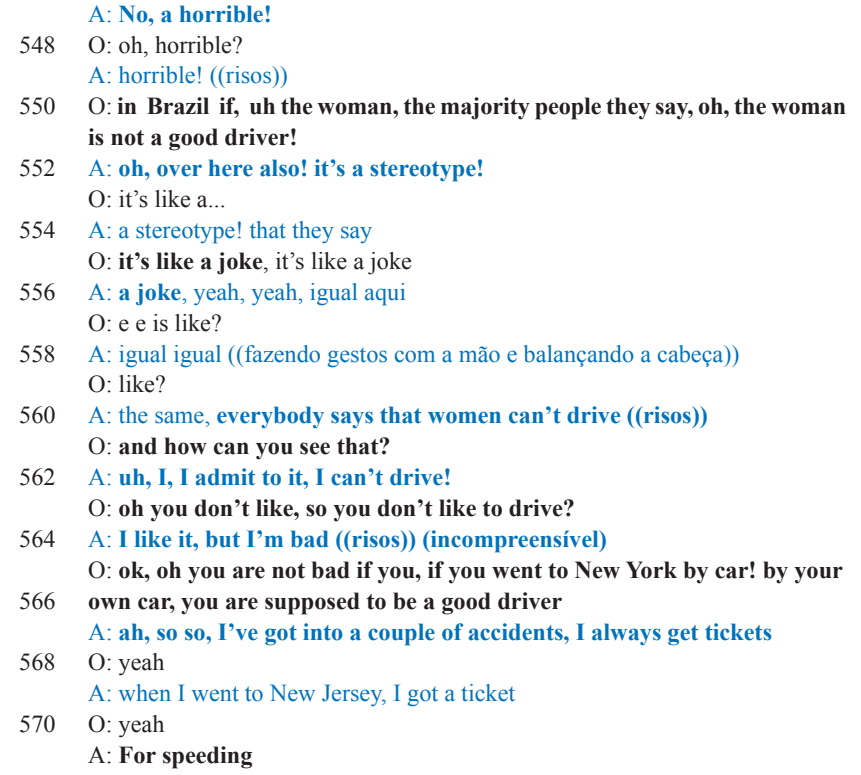

(Excerto 13-TT, Ashley e Orlando, 18/04/2012)

Ao perguntar a Ashley se ela se considera uma boa motorista (linha 544), há, no questionamento de Orlando, uma voz social que evoca o discurso machista de que "mulheres não sabem dirigir". Ainda que tente se desvincular desse discurso, explicando a Ashley que não é ele quem diz que "mulheres não são boas motoristas" mas é "a maioria das pessoas no Brasil" (linha 550), tal associação é inevitável, já que a pergunta possivelmente nem teria sido enunciada se Orlando tivesse como parceiro de teletandem um homem. Afinal, ao nos fundamentarmos na filosofia da linguagem bakhtiniana, entendemos que somos constituídos por diferentes vozes sociais, ainda que não nos demos conta disto: discurso é embate, confronto entre aquilo de que temos consciência e que explicitamos e aquilo que nos captura e se (re)vela na interação com o outro. Como afirma Bakhtin (2006),

o falante não é um Adão bíblico, só relacionado com objetos virgens ainda não nomeados, aos quais dá nome pela primeira vez. [...] Uma visão de mundo, uma corrente, um ponto de vista, uma opinião sempre têm uma expressão verbalizada. Tudo isso é discurso do outro (em forma pessoal ou impessoal), e este não pode deixar de refletir-se no enunciado. (BAKHTIN, 2006, p. 300).

Assim, o discurso machista não se relaciona propriamente à capacidade de as mulheres dirigirem, mas ao lugar/papel que historicamente lhes/nos foi reservado por tantos séculos: como coadjuvantes e sujeitas a provarem sua/nossa capacidade em atividades que ainda são associadas a homens ${ }^{6}$.

\footnotetext{
6 Sobre ideias sedimentadas e discursos de gênero no âmbito do teletandem, vide Costa (2015).
}

O discurso machista não só é reconhecido, mas corroborado por Ashley, ao concordar que "todo mundo" diz que mulheres não sabem dirigir. Há uma identificação cultural desse discurso machista. Contudo, Orlando é surpreendido quando Ashley se identifica com essa posição na qual as mulheres são colocadas pelo discurso machista de que não sabem dirigir. É curiosa a inversão que se dá em seguida, quando é o próprio Orlando quem tenta convencer a parceira do contrário, ou seja, de que se ela fez tal viagem de carro, ela deveria, sim, ser boa motorista. Ashley, então, pondera ("so so" - linha 567) e argumenta que se envolveu em "a couple of" acidentes (o termo em inglês tem uma conotação que permite mais de uma interpretação, dependendo do ponto de vista) e que sempre leva multas.

$\mathrm{O}$ efeito discursivo desse enunciado, de imediato, parece corroborar que Ashley, de fato, é uma motorista "horrível" (linha 540). Contraditoriamente, porém, não fica evidente se os acidentes foram causados por ela: em português, os enunciados "eu bati o carro" e "bateram no meu carro" têm sentidos diferentes. Em inglês, "I’ve got into a couple of acidentes" deixa o sentido ambíguo. Ademais, ao alegar que uma das multas que levou foi por excesso de velocidade, a imagem construída por Ashley contrasta com aquela construída pelo próprio discurso machista de que "mulher não dirige bem." Afinal, nesse discurso, a alta velocidade é, frequentemente, associada ao homem, e até mesmo à ideia de dirigir bem, se pensarmos, por exemplo, nos pilotos de esportes automotivos, uma área ainda dominada por homens.

Outro ponto que corrobora essa interpretação de que Ashley, apesar de se assumir "uma motorista horrível", pode, de fato, não se considerar assim, está no próprio argumento de Orlando de que alguém que não soubesse dirigir/fosse uma má motorista ("I can't drive")"I'm bad" - linhas 562 e 564) dificilmente faria uma viagem de 25 horas dirigindo. Ao afirmar que a ideia de que as mulheres não sabem dirigir é um estereótipo (linhas 545 e 547), Ashley parece deixar a dúvida sobre se ela se considera ou não uma boa motorista.

Portanto, o desfecho da conversa leva a uma reflexão sobre dois posicionamentos dos sujeitos que se opõem: Ashley, a mulher jovem que explicitamente diz não ser boa motorista, mas acaba deixando implícita uma resposta ao estereótipo levantado por seu parceiro de teletandem; e Orlando, o homem mais velho que explicitamente rechaça o estereótipo, distanciando sua voz daquelas vozes que o propagam, sem, contudo, obter êxito, porque ambos estão capturados por tal discurso.

É "cultural" dizer que mulher não sabe dirigir e isso está além das fronteiras geográficas do Brasil (linha 550) e dos Estados Unidos (linha 552). Para além de simples trocas de informações sobre cultura, é, no nível 
do discurso, no diálogo entre dois sujeitos situados historicamente e constituídos na relação eu-outro, que a noção de cultura emerge no teletandem.

\section{Considerações finais}

Os excertos de interações analisados exemplificam como as discussões sobre aspectos relacionados à noção de cultura emergem no contexto teletandem. Exemplificam, ainda, como podemos tecer relações discursivas a partir de um olhar translinguístico para o corpus.

Confrontar os dados de interações em teletandem por meio de uma perspectiva translinguística implica uma compreensão das vozes sociais e dos discursos que atravessam não apenas as diferentes formas de se entender a noção de cultura, mas também aquilo que é tratado nas interações por diferentes duplas de interagentes. Destarte, entender que cultura está na língua implica reconhecer vozes sociais presentes no discurso e produzir significados sobre elas.

Cabe, agora, desenvolvermos um olhar mais atento para a dimensão discursiva não apenas das interações, mas de todas as atividades que formam o contexto de teletandem institucional. Voltar o olhar de pesquisadores para a cultura como discurso e no discurso é estar na incompletude bakhtiniana dos sentidos atribuídos aos enunciados e depende, necessariamente, de diálogo entre outros sujeitos do discurso.

\section{Referências}

AMORIM, M. O pesquisador e seu outro: Bakhtin nas ciências humanas. São Paulo: Musa Editora, 2004.

AMORIM, M. Cronotopo e exotopia. In: BRAIT, B. Bakhtin: outros conceitos-chave. São Paulo: Contexto, 2010. p. 95-113.

ARANHA, S.; CAVALARI, S. M. S. A trajetória do projeto Teletandem Brasil: da modalidade institucional não-integrada à institucional integrada. The ESPecialist, v. 35, n. 2, p. 183-201, 2014

BAKHTIN, M. The Dialogic Imagination. Ed. Michael Holquist. Trans. Caryl Emerson and Michael Holquist. Austin: University of Texas Press, 1981.

BAKHTIN, M. Os gêneros do discurso. In: BAKHTIN, M. Estética da criação verbal. Trad. Paulo Bezerra. 4. ed. São Paulo: Martins Fontes, 2006.

BAKHTIN, M. Problemas da poética de Dostoievski. Trad. Paulo Bezerra. 5. ed. Rio de Janeiro: Forense Universitária, 2013a.

BAKHTIN, M. Questões de estilística no ensino da língua. Trad. Sheila Grillo \& Ekaterina Vólkova Américo. São Paulo: Editora 34, 2013b.

BAKHTIN, M./VOLOCHINOV. (1929). Marxismo e filosofia da linguagem. Trad. Michel Lahud e Yara Frateschi Vieira. 11. ed. São Paulo: Hucitec, 2004.
BHABHA, H. K. O local da cultura. Trad. Myriam Ávila, Eliana Lourenço de Lima Reis, Gláucia Renate Gonçalves. Belo Horizonte: Ed. UFMG, 1998.

BELZ, J. A. From the special issue editor. Language Learning \& Technology, v. 7, n. 2, p. 2-5, 2003. Disponível em: <http:// llt.msu.edu/vol7num2/speced.html >. Acesso em: 25 maio 2011.

BRAIT, B. Análise e teoria do discurso. In: BRAIT, B. (Org.). Bakhtin: outros conceitos-chave. São Paulo: Contexto, 2010.

BRAIT, B. Construção coletiva da perspectiva dialógica: história e alcance teórico-metodológico. In: FIGARO, R. (Org.). Comunicação e análise do discurso. São Paulo: Contexto, 2013, p. 79-98.

BRAMMERTS, H. Tandem language learning via the internet and the International E-Mail Tandem Network. In: LITTLE, D.; BRAMMERTS, H. (Eds.). A Guide to Language Learning in Tandem via the Internet. CLCS Occasional Paper, 46, 1996, p. 9-22.

BRAMMERTS, $\mathrm{H}$. et al. Aconselhamento individual em diferentes contextos Tandem. In: DELILLE, K. H.; CHICHORRO, A. (Orgs.). Aprendizagem Autónoma de línguas em Tandem. Coimbra: Colibri, 2002. p. 81-88.

DOOLY, M.; O'DOWD, R. Researching online foreign language interaction and exchange: theories, methods and challenges. Peter Lang Publishing, 2012. (Telecollaboration in Education, 3).

FERNANDES, C. A. Análise do discurso: reflexões introdutórias. São Paulo: Claraluz, 2008.

FIORIN, J. L. Interdiscursividade e intertextualidade. In: BRAIT, B. (Org.). Bakhtin: outros conceitos-chave. São Paulo: Contexto, 2010. p. 161-193.

FIORIN, J. L. Categorias de análise em Bakhtin. In: PAULA, L. de; STAFUZZA, G. (Org.). Círculo de Bakhtin: diálogos (in)possíveis. Série Bakhtin - Inclassificável. Campinas, SP: Mercado de Letras, 2011. v. 2, p. 33-48.

KRAMSCH, C. Third Culture and Language Education. In: WEI, L.; COOK, V. (Eds.). Contemporary Applied Linguistics. Volume One Language Teaching and Learning. London: Continuum International Publishing Group, 2009. Disponível em: <http://lrc.cornell.edu/events/past/2008-2009/papers08/ third.pdf>. Acesso em: 17 fev. 2014.

LEONE, P. Content Domain and Language Competence in Computer-mediated Conversation for Learning. Apples Journal of Applied Language Studies, v. 6, n. 2, p. 131-153, 2012.

MESSIAS, R. A. L. Teletandem e Formação de Professores: um contexto para reflexão sobre o ensino de línguas português/ espanhol. (mimeo)

O'DOWD, R. Intercultural communicative competence through telecollaboration. In: JACKSON, J. (Ed.). The Routledge Handbook of Language and Intercultural Communication. New York: Routledge, 2011. p. 342-358.

PAULA, L de. Círculo de Bakhtin: uma Análise Dialógica de Discurso. Revista de Estudos da Linguagem, Belo Horizonte, v. 21, n. 1, p. 239-258, jan.-jun. 2013.

SOBRAL, A. A arquitetônica de Luna Clara e Apolo Onze: uma reflexão metalinguística. Bakhtiniana, São Paulo, v. 8, n. 2, p. 220-240, jul.-dez. 2013. 
TELLES, J. A. Projeto Teletandem Brasil: Linguas Estrangeiras para Todos - Ensinando e Aprendendo linguas estrangeiras in-tandem via MSN Messenger. Faculdade de Ciências e Letras de Assis, UNESP. 2006. Disponível em: <http://www. teletandembrasil.org/site/docs/TELETANDEM_BRASIL completo.pdf>. Acesso em: 02 set. 2010.

TELLES, J.A. Teletandem: Uma proposta alternativa no ensino/aprendizagem assistidos por computadores. In: TELLES, J. A. (Org.). Teletandem: Um contexto virtual, autônomo e colaborativo para aprendizagem de línguas estran- geiras no século XXI. Campinas, SP: Pontes Editores, 2009. p. 43-61.

VASSALLO, M. L. Relações de poder em parcerias de teletandem. 2010. 296 f. Tese (Doutorado em Estudos Linguísticos) - Instituto de Biociências, Letras e Ciências Exatas, Universidade Estadual Paulista, São José do Rio Preto, e Università Ca’Foscari, Venezia, 2010.

Recebido: 15 de agosto de 2015

Aprovado: 26 de dezembro de 2015

Contato: maisazakir@gmail.com 